\title{
NeW Beginnings
}

\author{
Mark V. Boswell, MD, PhD
}

The New Year brings another issue of Pain Physician and a new Editor-in Chief of the journal. It is an honor for me to assume the editorship with the January 2004 issue. Dr. Curtis W. Slipman, the previous Editor-in-Chief has stepped down to pursue academic and clinical interests. He has done a wonderful job of guiding the development of the journal and I am happy to say that he has agreed to join the editorial advisory board, despite his busy schedule. I value his advice and friendship and look forward to working with him on future issues.

My initial involvement with the editorial process has been exciting and enlightening. I am impressed with the professionalism and commitment of the staff of Pain Physician. I am also pleased with the outstanding academic work of a large number of physicians and scientists dedicated to the advancement of the specialty of interventional pain management.

The current issue should provide a wide range of useful original articles, reviews, case reports and letters. There is something of interest for everyone interested in the science and practice of our growing specialty.

From Editor-in-Chief, Pain Physician. Dr. Boswell is Associate Professor of Anesthesiology, Chief, Pain Medicine Service, Director, Pain Medicine Fellowship, Department of Anesthesiology of Case School of Medicine and University Hospitals of Cleveland, Ohio. Address Correspondence: Mark V. Boswell, $\mathrm{MD}, \mathrm{PhD}$, Department of Anesthesiology, University Hospitals, 11100 Euclid Avenue, Cleveland, $\mathrm{OH}$ 44106

E-mail:mark.boswell@uhhs.com
Original studies include evaluations of fluoroscopically-guided caudal epidural injections, the value of Sarapin in neural blockade, epidural contrast flow patterns in patients with spinal stenosis and herniated discs, and the role of endorphins in cancer pain. In a novel study, restorative intradiscal injections are compared with IDET for chronic low back pain. Drs. Datta and Pai take a new look at the anatomy of the lumbar sympathetic chain, and propose a modified approach to lumbar sympathetic blockade. New development of techniques is also at the forefront in this issue.

Abuse of controlled substances by our patients continues to be a major issue for pain management physicians. Dr. Manchikanti and colleagues provide insight into the problem of identifying patients in your practice who are using illicit drugs. It appears that currently available and validated screening tools for controlled substance abuse fail to identify illicit drug use in patients receiving controlled substances. This article is important reading for interventional pain management physicians.

Raj, Shah, Kaye et al present an extensive review and update on the bleeding risks of procedures used in interventional pain practice, and provide a useful tool for assessing risk in individual patients. The review also provides a scholarly look at the complicated topic of hemostasis, coagulation, anticoagulation and thrombosis. Practicing physicians and physicians in training alike are encouraged to study this article.
Drs. Fortin and Weber provide an outstanding review of the fundamentals of musculoskeletal imaging, while Drs. Fortin and Wheeler provide an outstanding radiologic review of lumbar spinal stenosis.

There are a number of interesting case reports and technical notes of particular importance to interventional pain physicians. Cases examined include balloon kyphoplasty, wrong level disc surgery, and a complication of intrathecal cefazolin given during discography.

Dr. Giordano and colleagues provide a scholarly update on the current science of serotonin, focusing on the 5HT3 receptor and pain, including implications for therapeutics. It is anticipated that basic science updates of relevance to pain management physicians will become a regular feature of the journal.

Promoting ethical practice management continues to be an important mission of the American Society of Interventional Pain Practice Physicians. An article on practice management identifies legal issues that precipitate employment-related litigation, and suggests steps that physicians can take to implement lawful hiring practices. These recommendations can help you reduce the risk of costly employment suits while improving office efficiency, morale, and productivity.

I wish to thank the many contributors to this issue, whose efforts are appreciated. We welcome comments from you, the readers, as well as your observations and letters, and above all, your manuscripts. 